\title{
Neuraxial versus Peripheral Nerve Block for Postoperative Pain Management in Drug Abusers Undergoing Orthopedic Surgeries
}

\author{
Alaa Eid Mohammad, Ahmed Ali El-Shebiny, Michael Naser Saba Tomas \\ Anesthesiology and Intensive Care Department, Faculty of Medicine, Ain Shams University
}

\begin{abstract}
Background: While all surgical procedures are associated with some degree of pain, it is a well-accepted fact that orthopedic surgeries are some of the most painful. Despite the increasing interest and continuous advancement in postoperative pain management, more than half of the patients who undergo orthopedic surgeries experience inappropriate level of postoperative pain. Poorly treated pain can have negative impact on recovery especially owing to disruption in physiotherapy resulting in stiffness of joints and slow progress in mobility. In order to achieve good quality of postoperative analgesia, careful history should be taken from the patients about any coexisting medical conditions such as substance abuse or withdrawal, anxiety disorder, affective disorder, hepatic or renal impairment and any past history of poor pain management. Aim of the Work: The purpose of this study was to compare efficacy, side effects, opiate consumption and hemodynamic effects of neuraxial blocks versus peripheral nerves blocks placed under ultrasound guidance, for postoperative pain management in drug abusers undergoing orthopedic surgeries. Patients and Methods: Sixty patients presenting to Ain Shams University hospitals for orthopedic surgeries were enrolled in this prospective randomized controlled study after providing written consents. Participants were instructed about the study protocol and visual analogue scale (VAS). Approval was obtained from the research ethics committee of anesthesia and intensive care department, at Ain Shams University. In this study, all patients were preoperatively assessed for evaluation of their medical status, mode of trauma, post-traumatic critical symptoms or signs, hemodynamic stability, evidence of coagulopathy and any previous history or concurrent drug abuse. Results: This study included 60 drug-abuser patients, undergoing orthopaedic surgeries, starting from January 2018 till May 2018 at Ain Shams University Hospitals and randomly distributed within 2 groups, 30 patients each: Group A: EPI group, Group B: PNB group. As regard to age, gender, body weight, height, ASA and duration of surgery, there were no statistically significant differences between both groups (P-value >0.05). Regarding effects on hemodynamics and intraoperative ephedrine administration, the present study found statistically significant difference in the mean arterial blood pressure measured intra operatively with more drop in group A $(\mathrm{EPI})$ than group $\mathrm{B}(\mathrm{PNB})$ with a $(\mathrm{P}$ value $<0.001)$. Also there was significant increase in heart rate from baseline readings in group A compared to group B ( $\mathrm{P}$ value $<0.001)$. Statistically significant more incidence of intraoperative ephedrine administration was found in group A compared to group $\mathrm{B}$ with a $(\mathrm{P}$ value $<$ 0.001). Regarding incidence of postoperative side effects such as sedation, dizziness, nausea, vomiting and urine retention, there was statistically significant more incidence in group A (EPI) than group B (PNB) with a (P value < 0.001). Regarding postoperative pain assessment using VAS, opioids consumption, fulfillment of rehabilitation programs and hospital stay, there were no statistically significant differences between both groups ( $\mathrm{P}$ value $>0.05)$. Conclusion: The choice of continuous femoral and sciatic block technique placed under ultra-sound guidance for postoperative pain control provides equivalent analgesia, opioid consumption, postoperative rehabilitation and hospital stay with a lower incidence of hemodynamic side effects when compared to continuous epidural analgesia in drug-abuser patients undergoing orthopedic surgeries. It was also associated with decreased risk of postoperative side effects as sedation, dizziness, nausea andlor vomiting and urinary retention.
\end{abstract}

Keywords: Neuraxial, Peripheral Nerve Block, Drug Abusers, Orthopedic Surgeries

\section{INTRODUCTION}

While all surgical procedures are associated with some degree of pain, it is a well-accepted fact that orthopedic surgeries are some of the most painful. Despite the increasing interest and continuous advancement in postoperative pain management, more than half of the patients who undergo orthopedic surgeries experience inappropriate level of postoperative pain. Poorly treated pain can have negative impact on recovery especially owing to disruption in physiotherapy resulting in stiffness of joints and slow progress in mobility ${ }^{(\mathbf{1})}$.
In order to achieve good quality of postoperative analgesia, careful history should be taken from the patients about any coexisting medical conditions such as substance abuse or withdrawal, anxiety disorder, affective disorder, hepatic or renal impairment and any past history of poor pain management. In addition, preoperative patient awareness should be done to improve expectations, compliance and ability to effectively interact with pain management techniques ${ }^{(2)}$.

A common problem in managing postoperative pain in patients with active or former substance abuse disorders is under-treatment of pain due to fear of creating further addiction problems. Patients subsequently end up 
in significant pain and any requests for relief may be interpreted as "drug-seeking" behavior ${ }^{(3)}$.

Although different techniques are used, the best technique based on efficacy and safety has not been determined. General anesthesia combined with neuroaxial blockades, and peripheral nerve blocks represent the techniques used more often ${ }^{(4)}$.

Both techniques have different efficacy with advantages and disadvantages, however neuraxial blocks are probably used more often due to the quality and predictability of the anesthetic blockade, low cost, and easiness to perform. However, those techniques are not devoid of risks ${ }^{(5)}$.

\section{AIM OF THE WORK}

The purpose of this study was to compare efficacy, side effects, opiate consumption and hemodynamic effects of neuraxial blocks versus peripheral nerve blocks placed under ultrasound guidance, for postoperative pain management in drug abusers undergoing orthopedic surgeries.

\section{PATIENTS AND METHODS}

Sixty patients presenting to Ain Shams University hospitals for orthopedic surgeries were enrolled in this prospective randomized controlled study after providing written consents. Participants were instructed about the study protocol and visual analogue scale (VAS). Approval was obtained from the research ethics committee of anesthesia and intensive care department, Ain Shams University.

In this study all patients were preoperatively assessed for evaluation of their medical status.

Inclusion criteria: Adult patients aging 20-60 years old, drug abusers, physical status ASA I \& II undergoing emergency orthopedic surgeries with normal coagulation profile.

Exclusion criteria: Patients with the following conditions were excluded from the study: Refusal of the procedure or participation in the study. Physical status: ASA III or above Severe bleeding and hemodynamic instability. Anemia. Any past history or recent evidence of coagulopathy. Evidence of infection at injection site. Any contraindications of neuraxial block and peripheral nerve block.

Thetic protocol: All blocks were performed associated with general anaesthesia (to avoid effects of spinal anaesthesia on hemodynamics and postoperative pain) under complete aseptic techniques, using fenestrated sterile fields, sterile gloves, cap and face mask by the same anesthesiologist. Patients were assigned randomly using their medical record number (MRN) into two equal groups: Group A: $(\mathbf{n}=\mathbf{3 0})$ : patients receiving continuous epidural analgesia (EPI). Group B: $(\mathbf{n}=\mathbf{3 0})$ : patients receiving ultrasound guided continuous femoral and sciatic nerves block (PNB).

\section{Methodology}

Preoperative: Preoperative assessment was done including: History (focused on mode of trauma, post-traumatic critical symptoms and history of concurrent medical illness, coagulopathy or drug history). Clinical examination (focused on post-traumatic critical signs, level of consciousness and hemodynamic stability). Laboratory investigations essential preoperative laboratory investigations (focusing on normal coagulation profile \& adequate platelets level).

\section{Operative day:}

Technique: Upon arrival of the patient to the induction room and after ensuring baseline stable vital data, a suitable peripheral vein was cannulated, $10-30 \mathrm{mcq} / \mathrm{kg}$ midazolam was given for sedation and Ringer solution of $10 \mathrm{ml} / \mathrm{kg}$ started.

\section{Statistical analysis:}

Independent sample t-test was used to assess the statistical significance of the difference of a parametric variable between independent means of the study groups. Chi Square Test was used to examine the relationship between two qualitative variables but when the expected count is less than 5 in more than 20 $\%$ of the cells, Fisher's Exact Test was used.

\section{RESULTS}

Table (1): Disease classification.

\begin{tabular}{|c|c|c|c|c|c|c|c|c|}
\hline \multirow{3}{*}{ Disease } & \multicolumn{6}{|c|}{ Groups } & \multirow{2}{*}{\multicolumn{2}{|c|}{ Chi-Square }} \\
\hline & \multicolumn{2}{|c|}{ Group A } & \multicolumn{2}{|c|}{ Group B } & \multicolumn{2}{|c|}{ Total } & & \\
\hline & $\mathbf{N}$ & $\%$ & $\mathbf{N}$ & $\%$ & $\mathbf{N}$ & $\%$ & $\mathrm{X} 2$ & P-value \\
\hline Free & 14 & 46.67 & 17 & 56.67 & 31 & 51.67 & & \\
\hline DM & 1 & 3.33 & 2 & 6.67 & 3 & 5.00 & & \\
\hline HTN & 3 & 10.00 & 2 & 6.67 & 5 & 8.33 & & \\
\hline DM/HTN & 2 & 6.67 & 2 & 6.67 & 4 & 6.67 & & \\
\hline $\mathrm{HCV}$ & 6 & 20.00 & 5 & 16.67 & 11 & 18.33 & 3.915 & 0.790 \\
\hline $\mathrm{HBV}$ & 1 & 3.33 & 0 & 0.00 & 1 & 1.67 & & \\
\hline $\mathrm{HCV} / \mathrm{HBV}$ & 3 & 10.00 & 1 & 3.33 & 4 & 6.67 & & \\
\hline Asthmatic & 0 & 0.00 & 1 & 3.33 & 1 & 1.67 & & \\
\hline Total & 30 & 100.00 & 30 & 100.00 & 60 & \begin{tabular}{|l}
100.00 \\
\end{tabular} & & \\
\hline
\end{tabular}

Shows non- significant statistical difference between both groups (P-value $>0.05$ ).

Table (2): Mean arterial blood pressure. 


\begin{tabular}{|c|c|c|c|c|c|c|}
\hline & & \multicolumn{3}{|c|}{ Groups } & \multicolumn{2}{|c|}{ T-Test } \\
\hline & & Gro & up $A$ & Group B & \begin{tabular}{l|l}
$\mathbf{t}$ & \\
\end{tabular} & P-value \\
\hline \multirow{2}{*}{ MBP T1 } & Range & & -112 & $89-105$ & \multirow[b]{2}{*}{1.746} & \multirow[b]{2}{*}{.086} \\
\hline & Mea & 99.867 & \pm 6.580 & $97.133 \pm 5.501$ & & \\
\hline \multirow{2}{*}{ MBP T } & & & 107 & 105 & \multirow{2}{*}{1.558} & \multirow{2}{*}{125} \\
\hline & $\mathrm{Me}$ & 97.433 & \pm 5.367 & $95.067 \pm 6.357$ & & \\
\hline \multirow[b]{2}{*}{ IBP } & \begin{tabular}{|l|} 
Range \\
\end{tabular} & 65 & $\begin{array}{l}-85 \\
\end{array}$ & $\begin{array}{l}-107 \\
\end{array}$ & \multirow{2}{*}{3.936} & \multirow[b]{2}{*}{$<0.001^{*}$} \\
\hline & & 75.600 & \pm 6.066 & $96.300 \pm 5.421$ & & \\
\hline \multirow{2}{*}{$\mathrm{MBP}^{\prime}$} & & 60 & $\begin{array}{l}-75 \\
\end{array}$ & $85-105$ & \multirow{2}{*}{2.603} & \multirow{2}{*}{$<0.001^{*}$} \\
\hline & $\mathrm{Me}$ & 67.267 & \pm 4.785 & $97.367 \pm 5.505$ & & \\
\hline \multirow{2}{*}{ MBP T } & & 70 & -90 & $\begin{array}{l}-114 \\
\end{array}$ & \multirow{2}{*}{-15.638} & \multirow{2}{*}{$<0.001 *$} \\
\hline & $\mathrm{Me}$ & 79.000 & \pm 6.006 & $102.000 \pm 5.369$ & & \\
\hline \multirow{2}{*}{ MBP T } & & & -105 & $\begin{array}{ll}-106 \\
\end{array}$ & \multirow{2}{*}{-1.886} & \multirow{2}{*}{0.064} \\
\hline & & 95.200 & \pm 6.348 & $98.000 \pm 5.079$ & & \\
\hline \multirow{2}{*}{ MBP T } & & 90 & -110 & $\begin{array}{l}-115 \\
\end{array}$ & \multirow{2}{*}{-0.020} & \multirow{2}{*}{.985} \\
\hline & $\mathrm{Me}$ & 100.867 & \pm 5.692 & $100.900 \pm 7.429$ & & \\
\hline \multirow{2}{*}{ MBP 7} & & 87 & -112 & $\begin{array}{l}-110 \\
\end{array}$ & \multirow{2}{*}{0.18} & \multirow[b]{2}{*}{53} \\
\hline & $\mathrm{Me}$ & 99.967 & \pm 6.995 & \begin{tabular}{|l}
$99.667 \pm 5.529$ \\
\end{tabular} & & \\
\hline & & 87 & $\begin{array}{l}-109 \\
-\end{array}$ & $\begin{array}{l}-110 \\
\end{array}$ & \multirow[b]{2}{*}{${ }^{-1}$} & \\
\hline & & 98.367 & \pm 6.764 & $101.000 \pm 5.058$ & & \\
\hline & & 90 & $\begin{array}{l}-110 \\
\end{array}$ & \begin{tabular}{ll|}
-111 \\
\end{tabular} & & \\
\hline & Mean & 100.233 & \pm 6.229 & $100.133 \pm 5.600$ & & \\
\hline & & 92 & -110 & $90-112$ & & \\
\hline & $\mathrm{Me}$ & 101.600 & \pm 4.952 & $100.700 \pm 6.691$ & & \\
\hline M & & & $\begin{array}{l}-110 \\
\end{array}$ & $\begin{array}{|cc|}91-108 \\
\end{array}$ & 02 & \\
\hline & Mean \pm SD & 99.833 & \pm 6.000 & $99.433 \pm 4.960$ & & \\
\hline & $\mathrm{D}$ & 90 & -106 & $\begin{array}{|ll|}88 & -106 \\
\end{array}$ & & \\
\hline & Mean \pm SD & 97.767 & \pm 3.549 & $96.700 \pm 4.187$ & & \\
\hline & & 89 & $\begin{array}{l}-108 \\
\end{array}$ & $\begin{array}{l}-106 \\
\end{array}$ & & \\
\hline & Mean \pm SD & 96.700 & \pm 4.364 & $96.867 \pm 4.960$ & -0.13 & 0.09 \\
\hline & Range & 91 & $\begin{array}{l}-107 \\
\end{array}$ & $\begin{array}{l}-106 \\
\end{array}$ & & 60 \\
\hline $\mathrm{PPD}$ & Mean & 99.067 & \pm 4.076 & $98.500 \pm 4.313$ & & 60 \\
\hline & Range & 91 & -104 & -107 & & \\
\hline & Mean \pm SD & 98.067 & \pm 3.493 & $98.833 \pm 4.735$ & & \\
\hline & & 88 & 105 & -106 & & \\
\hline & Mean \pm SD & 97.333 & \pm 4.428 & $98.433 \pm 4.666$ & & \\
\hline
\end{tabular}

Concerning blood pressure monitoring, a drop in mean arterial blood pressure was more encountered in group A with statistically high significant values at $\mathrm{T} 3, \mathrm{~T} 4$ and $\mathrm{T} 5$ corresponding to the 10th, 20th and 30th minutes from skin incision respectively ( $\mathrm{P}$ value $<0.001$ ). Otherwise, difference between measurements done either intraoperatively or postoperatively were statistically non-significant ( $\mathrm{P}$-value $>0.05$ ).

Table (3): Ephedrine administration.

\begin{tabular}{|c|c|c|c|c|c|c|c|c|}
\hline \multirow{3}{*}{$\begin{array}{c}\text { Ephedrine } \\
\text { use }\end{array}$} & \multicolumn{6}{|c|}{ Groups } & \multirow{2}{*}{\multicolumn{2}{|c|}{ Chi-Square }} \\
\hline & \multicolumn{2}{|c|}{ Group A } & \multicolumn{2}{|c|}{ Group B } & \multicolumn{2}{|c|}{ Total } & & \\
\hline & $\mathbf{N}$ & $\%$ & $\mathbf{N}$ & $\%$ & $\mathbf{N}$ & $\%$ & $\mathbf{X} 2$ & $\begin{array}{c}\mathbf{P}- \\
\text { value }\end{array}$ \\
\hline No & $\begin{array}{l}1 \\
4\end{array}$ & $\begin{array}{c}46.6 \\
7\end{array}$ & $\begin{array}{l}3 \\
0\end{array}$ & $\begin{array}{c}100 . \\
00\end{array}$ & $\begin{array}{l}4 \\
4\end{array}$ & $\begin{array}{c}73.3 \\
3\end{array}$ & \multirow{3}{*}{$\begin{array}{c}21.8 \\
18\end{array}$} & \multirow{3}{*}{$\begin{array}{c}<0.00 \\
1^{*}\end{array}$} \\
\hline Yes & $\begin{array}{l}1 \\
6\end{array}$ & $\begin{array}{c}53.3 \\
3\end{array}$ & 0 & 0.00 & $\begin{array}{l}1 \\
6\end{array}$ & $\begin{array}{c}26.6 \\
7\end{array}$ & & \\
\hline Total & $\begin{array}{l}3 \\
0\end{array}$ & $\begin{array}{c}100 . \\
00\end{array}$ & $\begin{array}{l}3 \\
0\end{array}$ & $\begin{array}{c}100 . \\
00\end{array}$ & $\begin{array}{l}6 \\
0\end{array}$ & $\begin{array}{c}100 . \\
00\end{array}$ & & \\
\hline
\end{tabular}

Regarding to the intraoperative use of ephedrine to treat hypotension episodes, data showed significant higher incidence of ephedrine usage among group A ( $\mathrm{P}$ value $<0.001)$.

Table (4): Incidence of side effects.

\begin{tabular}{|c|c|c|c|c|c|c|c|c|}
\hline \multirow{3}{*}{$\begin{array}{l}\text { Side } \\
\text { effect }\end{array}$} & \multicolumn{6}{|c|}{ Groups } & \multirow{2}{*}{\multicolumn{2}{|c|}{ Chi-Square }} \\
\hline & \multicolumn{2}{|c|}{ Group A } & \multicolumn{2}{|c|}{ Group B } & \multicolumn{2}{|c|}{ Total } & & \\
\hline & $\mathbf{N}$ & $\%$ & $\mathbf{N}$ & $\%$ & $\mathbf{N}$ & $\%$ & $\mathrm{X} 2$ & $\begin{array}{c}\text { P- } \\
\text { value }\end{array}$ \\
\hline No & $\begin{array}{l}2 \\
0\end{array}$ & 66.67 & $\begin{array}{l}2 \\
8\end{array}$ & 93.33 & $\begin{array}{l}4 \\
8\end{array}$ & 80.00 & & \\
\hline Yes & $\begin{array}{l}1 \\
0\end{array}$ & 33.33 & 2 & 6.67 & $\begin{array}{l}1 \\
2\end{array}$ & 20.00 & $\begin{array}{c}6.66 \\
7\end{array}$ & $\begin{array}{c}0.010 \\
*\end{array}$ \\
\hline Total & $\begin{array}{l}3 \\
0\end{array}$ & $\begin{array}{c}100.0 \\
0\end{array}$ & $\begin{array}{l}3 \\
0\end{array}$ & $\begin{array}{c}100.0 \\
0\end{array}$ & $\begin{array}{l}6 \\
0\end{array}$ & $\begin{array}{c}100.0 \\
0\end{array}$ & & \\
\hline
\end{tabular}

The incidence of one or more side effect such as sedation, dizziness, nausea, and vomiting and/or urinary retention was higher in the group A compared to group B with a statistically significant difference ( $\mathrm{P}$ - value 0.05$)$.

Table (5): Pain assessment (VAS).

\begin{tabular}{|c|c|c|c|c|c|c|c|}
\hline & \multicolumn{4}{|c|}{ Groups } & \multicolumn{2}{|c|}{ T-Test } \\
\hline & & \multicolumn{2}{|c|}{ Group A } & \multicolumn{2}{|c|}{ Group B } & $\mathrm{t}$ & P-value \\
\hline \multirow{2}{*}{ PAIN T0 } & Range & 7.4 & 9.2 & 7.2 & 9.1 & \multirow[b]{2}{*}{0.562} & \multirow[b]{2}{*}{0.576} \\
\hline & Mean \pm SD & 8.263 & \pm 0.590 & 8.180 & \pm 0.557 & & \\
\hline \multirow{2}{*}{ PAIN T1 } & Range & 4 & $\begin{array}{l}-\quad 5.8 \\
\end{array}$ & 3.8 & $\begin{array}{l}-\quad 5.5 \\
\end{array}$ & \multirow[b]{2}{*}{1.958} & \multirow[b]{2}{*}{0.055} \\
\hline & Mean \pm SD & 4.830 & \pm 0.597 & 4.547 & \pm 0.522 & & \\
\hline \multirow{2}{*}{ PAIN T2 } & Range & 3.7 & $\begin{array}{l}-\quad 5.7 \\
\end{array}$ & 3.6 & $-\quad 5.2$ & \multirow[b]{2}{*}{1.755} & \multirow{2}{*}{0.085} \\
\hline & Mean \pm SD & 4.670 & \pm 0.605 & 4.430 & \pm 0.442 & & \\
\hline \multirow{2}{*}{ PAIN T3 } & Range & 4 & $\begin{array}{l}-\quad 5.7 \\
\end{array}$ & 3.9 & $\begin{array}{l}-\quad 5.7 \\
\end{array}$ & \multirow[b]{2}{*}{1.394} & \multirow{2}{*}{0.169} \\
\hline & Mean \pm SD & 4.793 & \pm 0.532 & 4.607 & \pm 0.504 & & \\
\hline \multirow{2}{*}{ PAIN T4 } & Range & 3.9 & -5.8 & 3.6 & $\begin{array}{l}-\quad 5.2 \\
\end{array}$ & \multirow{2}{*}{1.718} & \multirow{2}{*}{0.091} \\
\hline & Mean \pm SD & 4.697 & \pm 0.621 & 4.457 & \pm 0.447 & & \\
\hline \multirow{2}{*}{ PAIN T5 } & Range & 4 & $\begin{array}{l}-\quad 5.8 \\
\end{array}$ & 3.7 & $\begin{array}{l}-\quad 5.1 \\
\end{array}$ & \multirow{2}{*}{1.954} & \multirow{2}{*}{0.056} \\
\hline & Mean \pm SD & 4.573 & \pm 0.497 & 4.337 & \pm 0.440 & & \\
\hline \multirow{2}{*}{ PAIN T6 } & Range & 4 & -5.8 & 3.6 & $\begin{array}{l}-\quad 5.2 \\
\end{array}$ & \multirow{2}{*}{1.145} & \multirow{2}{*}{0.257} \\
\hline & Mean \pm SD & 4.537 & \pm 0.476 & 4.400 & \pm 0.448 & & \\
\hline \multirow{2}{*}{ PAIN T7 } & Range & 3.8 & -5.3 & 3.7 & - & \multirow{2}{*}{1.796} & \multirow{2}{*}{0.078} \\
\hline & Mean \pm SD & 4.620 & \pm 0.529 & 4.400 & \pm 0.413 & & \\
\hline
\end{tabular}

Pain assessment (VAS) showed no statistically significant difference between both groups ( $\mathrm{P}$ value $>0.05)$.

\section{DISCUSSION}

Orthopedic surgeries are associated with severe postoperative pain. Inadequate analgesia can produce unnecessary distress, suboptimal fulfillment of rehabilitation program and medical complications due to immobility. These factors are likely to delay rehabilitation. A number of analgesic strategies have been adopted to minimize postoperative pain after orthopedic surgeries. Studies suggested that regional techniques provide superior pain relief and faster postoperative rehabilitation than systemic analgesia.

This study was conducted on 60 patients drug abusers, either males or females, ASA I-II undergoing orthopedic surgeries to compare efficacy, side effects, opiate consumption, hemodynamic effects, hospital stay and 
postoperative rehabilitation between group (A) (EPI) receiving continuous femoral and sciatic nerves block placed under ultrasound guidance versus group (B) receiving continuous epidural analgesia for postoperative pain management.

The incidence of ephedrine administration intra-operatively was found to be statistically significant being higher in group A compared to group $\mathbf{B}$ with a $\mathrm{P}$ value $<0.001$.

Regarding to pain assessment, we compared efficacy of analgesia between both groups using VAS. Patients were assessed in the PACU, on the first and second postoperative days, and in the morning of the third postoperative day. Statistical analysis showed no significant difference between both groups ( $\mathrm{P}$ value $>0.05$ ).

The results showed that no significant difference in pain scores between the two groups: continuous femoral nerve block and continuous epidural analgesia in patients undergoing knee replacement surgery measured at rest, during continuous passive movement and during physiotherapy on post-operative days 1 and 2 .

The results of the present study revealed that the resting VAS scores of the CEI group were significantly less than those of the CFB group at $\mathrm{H} 6$ and $\mathrm{H} 12$, but they were similar at $\mathrm{H} 1$ which may be attributed to sparing the sciatic nerve in their study. During mobilization, the VAS of the CEI and CFB groups showed no significant differences during the study period.

Also there was statistically significant difference in pain assessment using VAS at 6 hours postoperatively being $2.32 \pm 1.1$ in epidural group compared to $4.26 \pm 1.09$ in the femoral group ( $\mathrm{P}$ value $<0.001$ ), after which there was a declining trend and scores were essentially similar from $24 \mathrm{~h}$.

In the present study we compared morphine consumption using the patient controlled analgesia (PCA) device. Both groups used their PCA, yet no significant difference detected (Group A $14.533 \pm 10.868$ versus group B $17.567 \pm 8.042$ ) with a $\mathrm{P}$ value 0.224 .

The results indicated that no difference was found between the groups in the number of patients requiring IV morphine (CFNB 12 versus CEA 11) or in the mean dosage of morphine (CFNB $44 \mathrm{mg}$ versus CEA 53mg).
The present results stated that PCA morphine usage was the same in both groups in the $1^{\text {st }}$ and $2^{\text {nd }}$ postoperative days being $32.6 \pm 26$ and $32.3 \pm 25.7$ with a P value 0.83 in the EPI group versus $31 \pm 26$ and $30.2 \pm 26.3$ in the PNB group respectively with a $\mathrm{P}$ value 0.78 .

It is worthy to indicate that our conclusion disagree with those found by Shanthanna et al. ${ }^{(6)}$ who stated that despite the higher incidence of PONV which was twice more common in the continuous epidural group compared to continuous femoral group yet no statistically significant difference could be detected ( $\mathrm{P}$ value 0.4 ). Also in their study, only one patient in the femoral group had urinary retention compared to four patients in the epidural group which was statistically nonsignificant ( $\mathrm{P}$ value 0.34). Failure to obtain statistical significant difference was probably due to the small number of subjects.

On the other hand, our findings seem to agree with those of Barrington et al. ${ }^{7)}$ who stated that there were no significant differences between both groups regarding postoperative range of movement in the operative knee during postoperative days $1-5$. There was also non difference between the groups in the number of patients who achieved 90 degrees of flexion on continuous passive motion by postoperative day 3 and who could walk with crutches by postoperative day 4 or climb one step by postoperative day 5 . Also there was no difference between the groups in hospital length of stay (mean of $5.3 \pm 1.1$ days in CFNB group versus5.4 \pm 1.1 days in CEA group).

The present results also concur those of Zaric et al. ${ }^{(8)}$, who found no significant difference in fulfillment of the mobilization program and in the degrees of active knee flexion between both the groups as evaluated by physiotherapists. Duration of admission was found to be similar for both groups being 7 days $(6,16)$ in the EPI group and 8 $(6,10)$ in the PNB group $(\mathrm{P}$ value $=0.6)$.

\section{CONCLUSIONS}

The presented study justified the choice of continuous femoral and sciatic block technique placed under ultra-sound guidance for postoperative pain control provides equivalent analgesia, opioid consumption, postoperative rehabilitation and hospital stay with a lower incidence of hemodynamic side effects when compared to continuous epidural analgesia in 
drug-abuser patients undergoing orthopedic surgeries. It is also associated with decreased risk of postoperative side effects such as sedation, dizziness, nausea andlor vomiting and urinary retention.

\section{REFERENCES}

1. Srivastava U, Kumar A, Saxena $S$ et al. (2007): lumbar plexus block for postoperative analgesia following hip surgery: a comparison of "3in 1"and psoas compartment block. Indian J Anaesth., 51(2):127-30.

2. Chris $\mathbf{T}$ (2003): Postoperative pain. Virtual Anesthesia Textbook. Last Modification, 85-99.

3. https://pdfs.semanticscholar.org/3f08/d30263d 900b05e85c1db3e885fc62ef6f5c1.pd

4. Türker G, Uçkunkaya N, Yavasçaoglu B (2003): Comparison of the catheter-technique psoas compartment block and the epidural bock for analgesia in partial hip replacement surgery. Acta Anaesthesiol Scand., 47:30-6.

5. Horlocker $T$ and Wedel $D$ (1998): Anticoagulation and Neuroaxial block: historical perspective, anesthetic implications and risk management. Reg Anesth Pain Med., 23(2):129-34.

6. Shanthanna H, Huilgol M, Manivackam $V$ et al. (2012): Comparative study of ultrasoundguided continuous femoral nerve blockade with continuous epidural analgesia for pain relief following total knee replacement. Indian Journal of Anesthesia, 56:270-5.

7. Barrington M, Olive D, Low $\mathrm{K}$ et al. (2005): Continuous femoral nerve blockade or epidural analgesia after total knee replacement: a prospective randomized controlled trial. Anesthesia \& Analgesia, 101(6): 1824-1829.

8. Zaric D, Boysen $\mathrm{K}$, Christiansen $\mathrm{C}$ et al. (2006): A comparison of epidural analgesia with combined continuous femoral-sciatic nerve blocks after total knee replacement. Anesthesia \& Analgesia, 102(4): 1240-1246. 